\title{
Center of Pressure Feedback for Controlling the Walking Stability Bipedal Robots using Fuzzy Logic Controller
}

\author{
Afrizal Mayub ${ }^{1}$, Fahmizal $^{2}$ \\ ${ }^{1}$ Graduate School of Science Education, University of Bengkulu, Indonesia \\ ${ }^{2}$ Department of Electrical and Informatics Engineering, Vocational College, Universitas Gadjah Mada, Indonesia
}

\begin{tabular}{l} 
Article Info \\
\hline Article history: \\
Received May 27, 2018 \\
Revised Aug 2, 2018 \\
Accepted Aug 9, 2018 \\
\hline
\end{tabular}

Keyword:

Bipedal robot

Center of pressure

Fuzzy logic controller

Walking stability

\begin{abstract}
This paper presents a sensor-based stability walk for bipedal robots by using force sensitive resistor (FSR) sensor. To perform walk stability on uneven terrain conditions, FSR sensor is used as feedbacks to evaluate the stability of bipedal robot instead of the center of pressure $(\mathrm{CoP})$. In this work, CoP that was generated from four FSR sensors placed on each foot-pad is used to evaluate the walking stability. The robot $\mathrm{CoP}$ position provided an indication of walk stability. The CoP position information was further evaluated with a fuzzy logic controller (FLC) to generate appropriate offset angles to be applied to meet a stable situation. Moreover, in this paper designed a FLC through CoP region's stability and stable compliance control are introduced. Finally, the performances of the proposed methods were verified with 18-degrees of freedom (DOF) kid-size bipedal robot.
\end{abstract}

Copyright (C) 2018 Institute of Advanced Engineering and Science. All rights reserved.

Corresponding Author:

Afrizal Mayub,

Graduate School of Science Education,

University of Bengkulu,

W.R. Supratman Road, 38371, Bengkulu, Indonesia.

Email: afrizalmayub@unib.ac.id

\section{INTRODUCTION}

The control of a bipedal robot is a challenging task due to the many degrees of freedom involved and the nonlinear and hard-to-stabilize dynamics [1], [2]. Bipedal robot structure is one of the most flexible forms of a walking robot. A bipedal robot has the same mechanism of action as a human and capable of walking in an environment containing uneven terrain, slope, stairs, obstacles, etc. [3]-[7].

Bipedal stability during walking motion is a critical fact in preventing the robot from falling down and causing the human or itself damages. The Zero Moment Point (ZMP) method is often used as a stability criterion for a walking biped robot [8]-[14]. We have found in the literature the use of force sensors placed under the feet. In [15] the authors proposed a Fuzzy control scheme in which the controlled variable is the coordinate compensation of the trunk only in the sagittal plane, used to move the measured ZMP to the desired ZMP, which is obtained from force sensors placed at the robot's feet.

Another related work [16] also proposes a cooperative control scheme to achieve lateral balance of a biped robot in the coronal plane, tested under disturbing conditions such as changes in the floor inclination and external forces applied to the body. The control system is composed of one master controller in charge of commanding the legs servomotors and two proportional Fuzzy controllers, one for each foot, which compute the Center of Pressure (CoP) under each foot and generate a control action to move the hips-ankles servomotors in order to return the CoP to a stable region.

In [17] analyzed ZMP was analyzed from human walker wearing robot feet as shoes. Some researchers proposed a flexible shoe system for biped robots to an optimized energy consumption of the lateral plane motion [18]. Kitti Suwanratchatamanee et al.[19] proposed a haptic sensing foot system for humanoid robots. They investigate two different kinds of implementations: one is an active tactile sensing 
technique to recognize a contacting ground slope. The other is to balance the robot body with one leg for human-robot interaction.

Reference [20] proposed a fuzzy controller to realized biped walking on the slope with the desired ZMP trajectory. In [21] proposed a dynamic balance control (DBC), which includes Kalman filter (KF) and the fuzzy motion controller (FMC), was also designed to keep the body balance and make the biped walking following the desired ZMP reference. In addition, KF is utilized to estimate the system states and reduced the effect caused by noise.

Stability is a vital criterion of bipedal robots in dynamic or static walking. The CoP located at the position under the foot bottom should affect bipedal walking stability. Thus the study of the CoP region for which a bipedal robot remains stable is a chalenge. Stable walking of a bipedal robot can be realized by balancing two types of force. First is the resultant force of gravity and the inertia produced by the motion of the robot. The other is the ground reaction force acting on both feet of the robot. In this paper, we developed stability walking bipedal robot in the second perspective. We refer the point associated with contact forces as CoP.

In this paper, we propose a method to control bipedal robot to have a stable walking on uneven terrain. Through an intelligent control such as fuzzy logic control (FLC). The major contributions of this paper are follows: 1) development and improvement of walking stability of bipedal robot based on Force Sensitive Resistor (FSR) sensor; 2) development of a foot pad sensor by using FSR; 3) design a FLC for CoP region's stability and stable compliance control; and 4) presents the practical effectiveness of this control scheme by experiments with HuroEvolutionJR kid size bipedal robot.

The remainder of this paper is organized as follows. In Section II, Strict definitions of CoP and ZMP are specified and body posture control bipedal robot also walking method of a bipedal robot. Section III elaborates the control system architectures especially on a fuzzy system for this work. Section IV presents several simulation results which show the effectiveness and merit of the proposed methods. Section V concludes the paper with remarks and suggestions for future works

\section{RESEARCH METHOD}

\subsection{Center of pressure (CoP) and zero moment point (ZMP) definition}

The concept of ZMP [22] is introduced under the assumption that a robot walks on a flat floor and the frictional forces are strong enough to compensate the ground reaction forces tangential to the ground. $\mathrm{ZMP}$, is the point on the surface of the foot where a resultant force $\mathrm{R}\left(\boldsymbol{F}_{\boldsymbol{R}}\right)$ can replace the force distribution shown in Figure 1. Mathematically, the ZMP can be calculated from a group of contact points $\boldsymbol{P}_{\boldsymbol{i}}$ for $i=1, \ldots$, $N$ with each force vector $\boldsymbol{f}_{\boldsymbol{i}}$ associated with the contact point.

$$
Z M P=\frac{\sum_{i=1}^{N} P_{i} f_{i z}}{\sum_{i=1}^{N} f_{i z}}=\frac{\sum_{i=1}^{N} P_{i} f_{i z}}{f_{z}}
$$

In this definition, the ZMP can never leave the support polygon. If the floor is assumed horizontal, the torque reduces to at the ZMP. The position of CoP, which is a point on the ground plane, where the ground reaction force is applied, is often considered to be an equivalent of ZMP, since they coincide while the robot is balanced. Therefore, the actual position of ZMP can be found using force sensors located on the soles of a robot. With these sensors, the center of pressure can be calculated on the feet, and the ZMP can be directly measured.

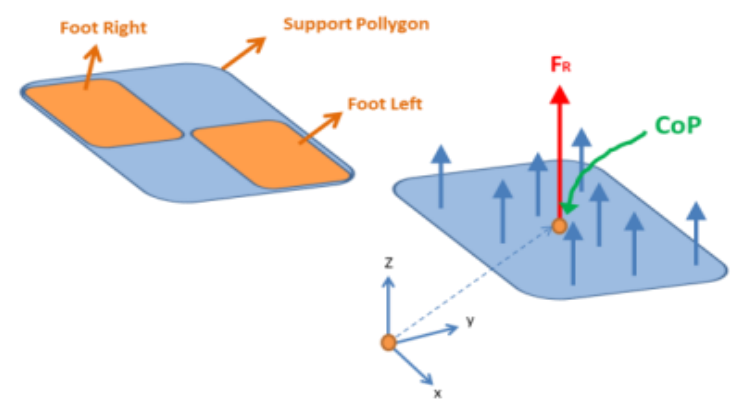

Figure 1. Support polygon and CoP position based on the total sum of the contact forces FR acts 


\subsection{Determining CoP position}

We can calculate the resultant force by using the center of area $(\mathrm{CoA})$ technique. In this paper, we developed four force sensitive resistor (FSR) sensors which were attached to the sole of the foot. There are two step calculations in order to know the CoP position which is related to the gait phases, i.e, single support phase (SSP) and double support phase (DSP). Figure 2 shows the CoP position when the bipedal robot on the SSP. The coordinates A, B, C, D are described by $\mathrm{P}_{\mathrm{A}}\left(\mathrm{x}_{\mathrm{PA}}, \mathrm{y}_{\mathrm{PA}}\right), \mathrm{P}_{\mathrm{B}}\left(\mathrm{x}_{\mathrm{PB}}, \mathrm{y}_{\mathrm{PB}}\right), \mathrm{P}_{\mathrm{C}}\left(\mathrm{x}_{\mathrm{PC}}, \mathrm{y}_{\mathrm{PC}}\right)$ and $\mathrm{P}_{\mathrm{D}}\left(\mathrm{x}_{\mathrm{PD}}, \mathrm{y}_{\mathrm{PD}}\right)$. So, we can calculate the CoP position as follows for SSP phase as indicated in (2)-(3).

$$
\begin{aligned}
& x_{C o P}=\frac{f_{A} x_{P A}+f_{B} x_{P B}+f_{C} x_{P C}+f_{D} x_{P D}}{f_{A}+f_{B}+f_{C}+f_{D}} \\
& y_{C o P}=\frac{f_{A} y_{P A}+f_{B} y_{P B}+f_{C} y_{P C}+f_{D} y_{P D}}{f_{A}+f_{B}+f_{C}+f_{D}}
\end{aligned}
$$

Where $f_{A}, f_{B}, f_{C}, f_{D}$, are the force at A, B, C, D point achieved through FSR sensors and explained in (4)-(7).

$$
\begin{aligned}
& x_{P A}=F L-d x A ; y_{P A}=F W-d y A \\
& x_{P B}=F L-d x B ; y_{P B}=d y B \\
& x_{P C}=d x C ; y_{P C}=F W-d x C \\
& x_{P D}=d x D ; y_{P D}=d x D
\end{aligned}
$$

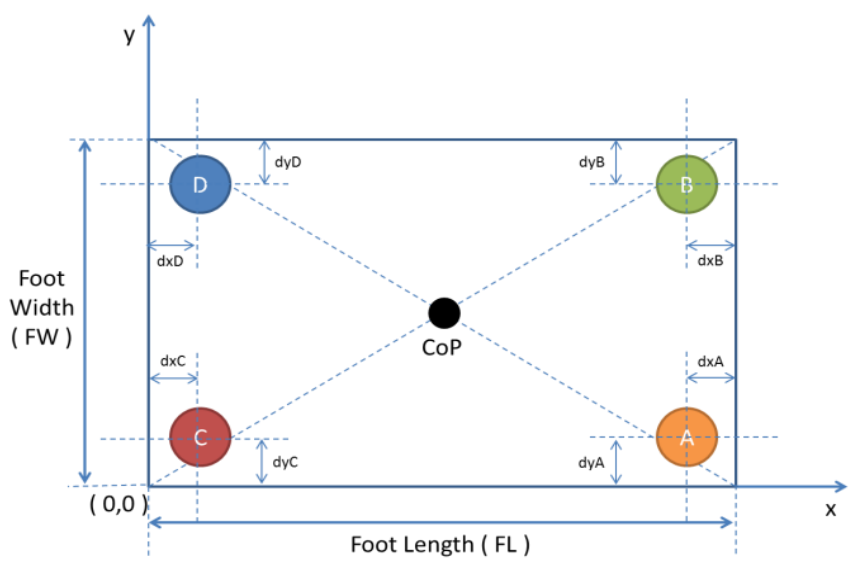

Figure 2. CoP position when the bipedal robot on SSP phases

Figure 3(a) shows DSP gait phases. The coordinate A1, B1, C1, D1, A2, B2, C2 and D2 are described by PA1 ( $\left.\mathrm{x}_{\mathrm{PA} 1}, \mathrm{y}_{\mathrm{PA} 1}\right), \mathrm{PB} 1\left(\mathrm{x}_{\mathrm{PB} 1}, \mathrm{y}_{\mathrm{PB} 1}\right), \mathrm{PC} 1\left(\mathrm{x}_{\mathrm{PC} 1}, \mathrm{y}_{\mathrm{PC} 1}\right), \mathrm{PD} 1\left(\mathrm{x}_{\mathrm{PD} 1}, \mathrm{y}_{\mathrm{PD} 1}\right), \mathrm{PA} 2\left(\mathrm{x}_{\mathrm{PA} 2}, \mathrm{y}_{\mathrm{PA} 2}\right), \mathrm{PB} 2$ $\left(\mathrm{x}_{\mathrm{PB} 2}, \mathrm{y}_{\mathrm{PB} 2}\right), \mathrm{PC} 2\left(\mathrm{x}_{\mathrm{PC} 2}, \mathrm{y}_{\mathrm{PC} 2}\right)$ and $\mathrm{PD} 2\left(\mathrm{x}_{\mathrm{PD} 2}, \mathrm{y}_{\mathrm{PD} 2}\right)$. When the bipedal robot on stand still conditions, the ideal $\mathrm{CoP}$ position is depicted on Figure 3(b). In this condition the force sensing is distributed with same value at all point. The CoP position located in circle black. 


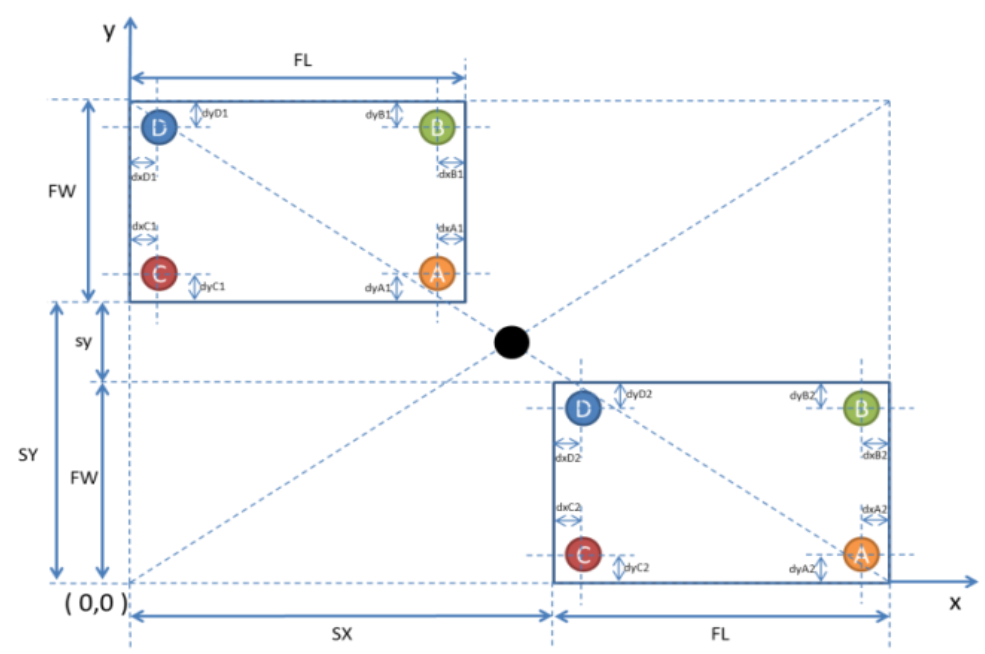

(a)

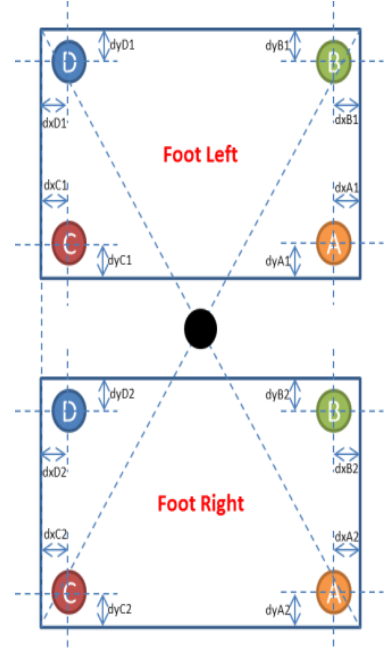

(b)

Figure 3. (a) CoP position when the bipedal robot on DSP phases and (b) CoP position when the bipedal robot on stand still conditions

\subsection{Foot pad sensor development}

FSR is sensors that allow detecting physical pressure, squeezing and weight. The FSR is made of two layers separated by a spacer. The higher force will push the active element dots closer to the semiconductor and makes the resistance go down. In this paper, we used FSR from Interlink 402 model. The easiest way to measure FSR sensor is using a voltage divider technique as shown in Figure 5. The junction point resistor up with FSR resistor is connected to the analog input of a microcontroller such as an Arduino. Four FSR sensors are equipped at the corners of each foot as shown in Figure 4. In order to minimize impact and deformation, and also to distribute the repulsive force, the sole is composed of plate up, plate down and a rubber plate. The FSR sensors are fixed between the two plates
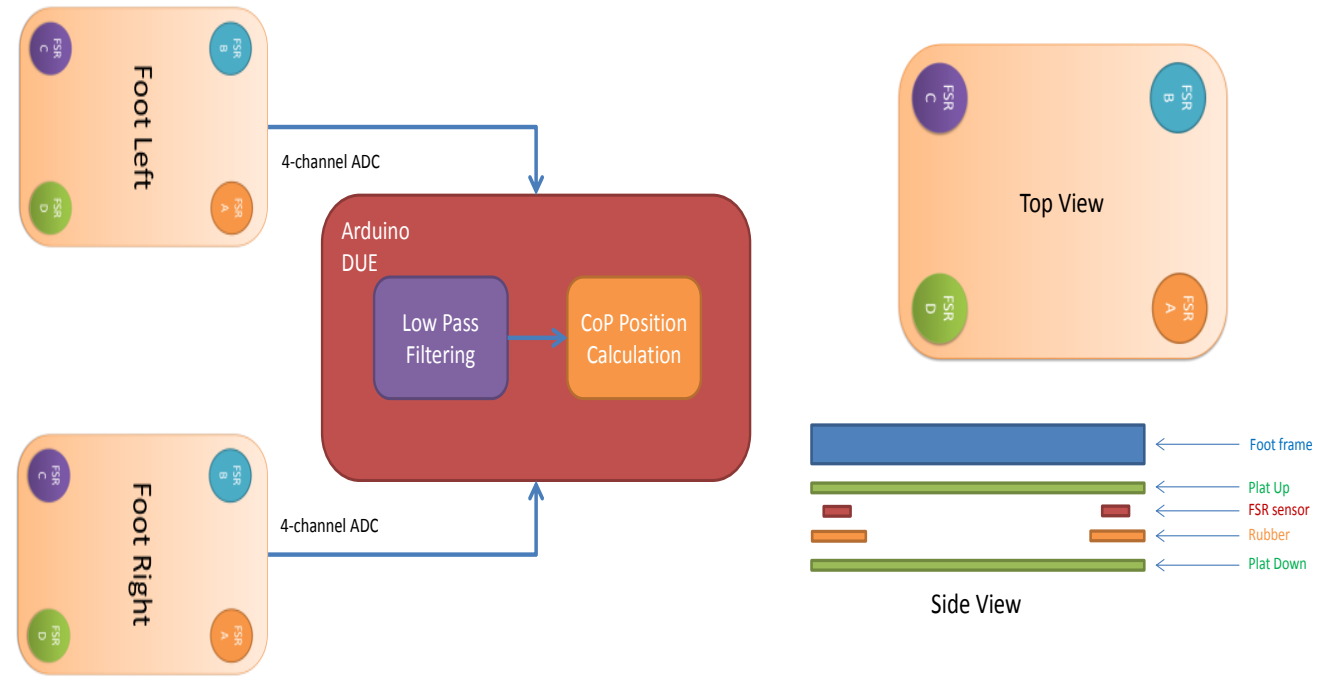

Figure 4. Foot pad sensor development architectures

Suppose a FSR sensor has already set by a calibration processed, then it can proceed for further investigation. As mentioned in the datasheet, FSR data is characterized by a low frequency region. Therefore, our system compensates those sensor data by implementing low-pass filter (LPF). Theoretically, a LPF denote as in (8). 


$$
v_{\text {in }}(t)-v_{\text {out }}(t)=R C \frac{d v_{\text {out }}}{d t}
$$

Let's simplify the input and output at evenly spaced points in time, then we can derive simplicity as in (9).

$$
x_{i}-y_{i}=R C \frac{y_{i}-y_{i-1}}{\Delta_{T}} y_{i}=x_{i}\left(\frac{\Delta_{T}}{R C+\Delta_{T}}\right)+y_{i-1}\left(\frac{R C}{R C+\Delta_{r}}\right) y_{i}=\alpha x_{i}+(1-\alpha) y_{i-1}
$$

where $\alpha \square \frac{\Delta_{T}}{R C+\Delta_{T}}, R C=\frac{1}{2 \pi f_{c}}, f_{c}$ denotes as the cut-off frequency, $\Delta_{T}$ is the sampling period and the smoothing factor $\alpha$ lies in $0 \leq \alpha \leq 1$.
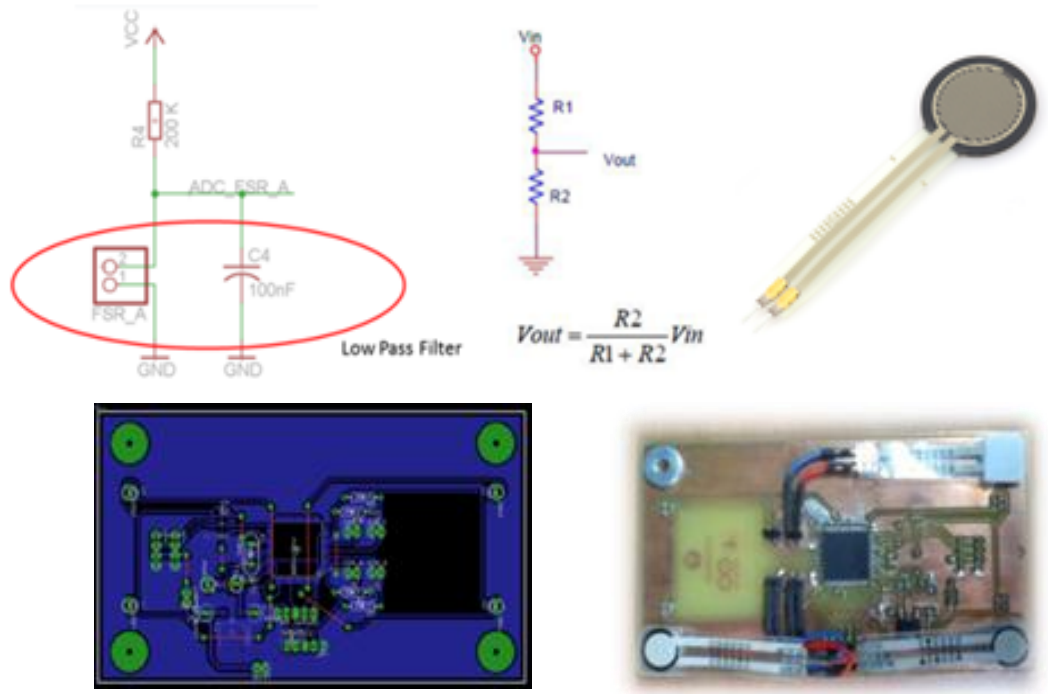

Figure 5. The FSR sensors are fixed between the two plates and voltage divider configuration at FSR with low pass filtering

\subsection{Body posture control on bipedal robot}

There are two ways in order to control the body posture bipedal robot, i.e. inverse kinematics and inverse kinematic with adding some theta offset to each joint motor. In three dimensional motion, frontal plane (roll movement) and sagittal plane (pitch movement) as shown in Figure 6(a) are contained with ten joints servo motor each leg. Table 1 is described the frontal and sagittal plane joint names

There are several parameters that will be used to adjust the posture of a bipedal robot as depicted in Figure 6(b). In this paper, we adjusting the hip_x_offset of our bipedal robot. The range operation of hip_x_offset is from -3 until 3 with cm units.

Table 1. The Frontal and Sagitall plane joint names of Bipedal Robot

\begin{tabular}{cccl}
\hline \multicolumn{2}{c}{ Frontal plane (roll) } & \multicolumn{2}{c}{ Sagittal plane (pitch) } \\
\hline$\theta_{2 L}$ & left hip roll & $\theta_{1 L}$ & left hip pitch \\
$\theta_{4 L}$ & left ankle roll & $\theta_{3 L}$ & left knee pitch \\
$\theta_{2 R}$ & right hip roll & $\theta_{5 L}$ & left ankle pitch \\
$\theta_{4 R}$ & right ankle roll & $\theta_{1 R}$ & right hip pitch \\
& & $\theta_{3 R}$ & right knee pitch \\
& & $\theta_{5 R}$ & right ankle pitch \\
\hline
\end{tabular}




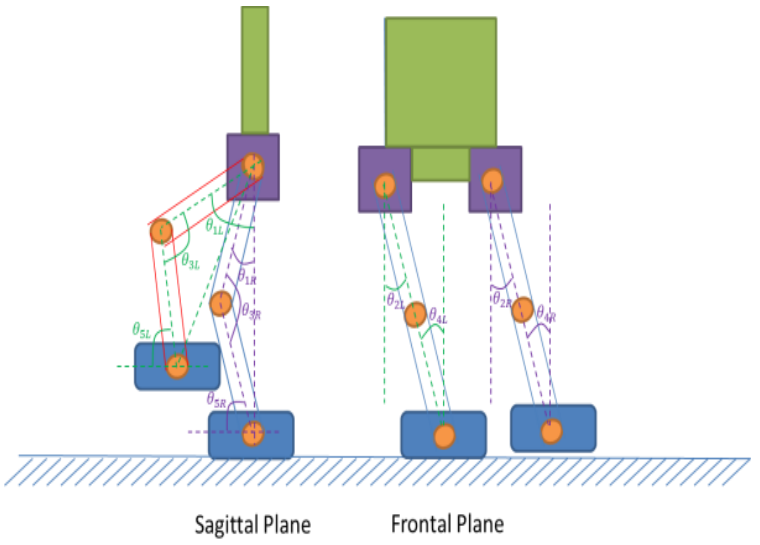

(a)

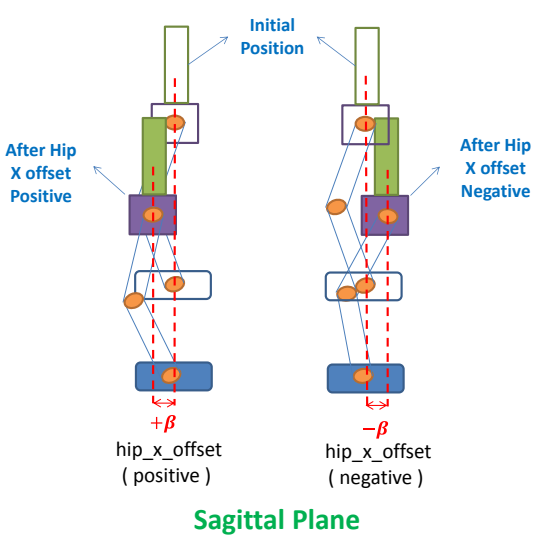

(b)

Figure 6. (a) Sagittal and frontal plane in a bipedal robot (b) Hip_x_offset parameters

\subsection{Walking method of bipedal robot}

Based on the human way of walking, bipedal robot walks divide into two phases, namely single support phases (SSP) and double support phases (DSP) [23]. In the beginning of walking, both of the feet are in touch with the base, which called DSP as described in Figure 7. The overall locomotion control system can be designed as shown in Figure 8 . At the beginning, the $\left(x_{c m d}, y_{c m d}, \theta_{c m d}\right)$ were commands that may be generated from an autonomous navigator or user's command, where $\left(x_{c m d}, y_{c m d}, \theta_{c m d}\right)$ are relative translational landing position of a swing foot with respect to a support foot; $\theta_{c m d}$ is the relative landing foot heading angle. Hence, the $\left(x_{c m d}, y_{c m d}, \theta_{c m d}\right)$ command is an omnidirectional walking command for bipedal robots that can be used to process footprint placement trajectory planning [24].

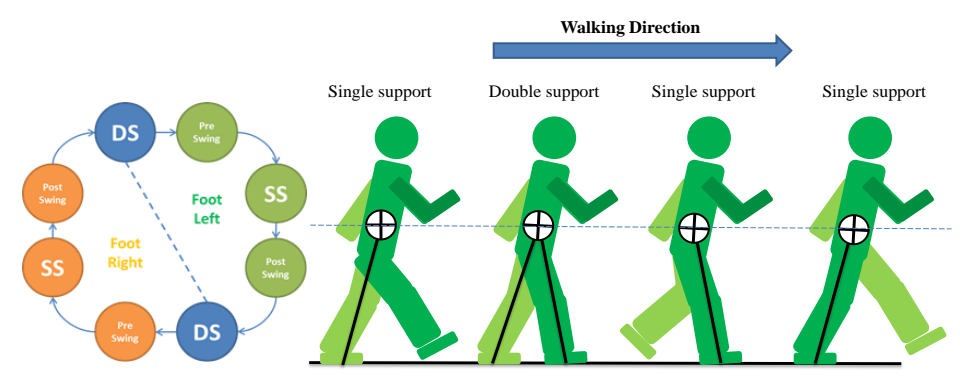

Figure 7. Human walking gait phase

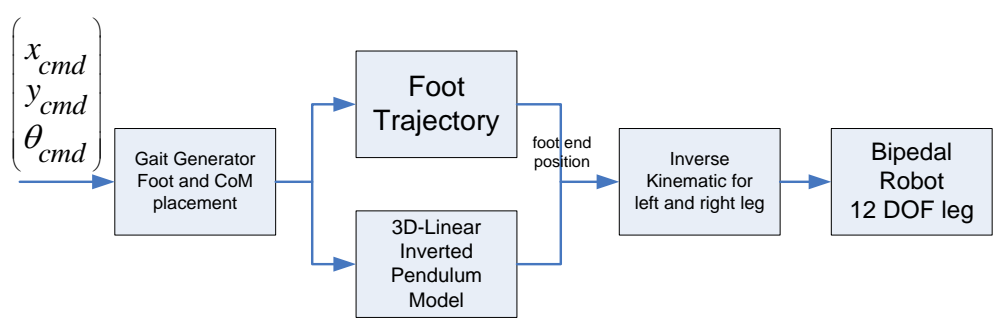

Figure 8. Bipedal robot locomotion control system

To achieve the trajectory of planes locomotion, the end position of each foot is also required. The trajectory of the swing foot is generated from a cycloid curve which can be indicated in (10)-(12). It is noted that $\left(x_{s}, y_{s} . z_{s}\right)$ are the position of the swing foot; Length, Height and Shift are the desired strike length, the strike height and the shift distance; $\rho$ is the time percentage of the period time when the foot reaches the 
highest position; $T_{s}$ is the period time. To get the real robot rotation based on the desired rotation, (13) is utilized to do so, where $T_{\theta c}$ is the rotation time constant. As a consequence, the gait trajectory can be obtained as the swing foot trajectory and the CoM trajectory. The inverse kinematics (IK) can be applied to the gait trajectory to find the joint angles of the bipedal leg model. The joint commands were sent to the servomotors.

$$
\begin{aligned}
& x_{s}(t)=\frac{\text { Length }}{2 \pi}\left[2 \pi \frac{t}{T_{s}}-\sin \left(2 \pi \frac{t}{T_{s}}\right)\right] ; 0 \leq t \leq T_{s} \\
& y_{s}(t)=\frac{\text { Shift }}{2 \pi}\left[2 \pi \frac{t}{T_{s}}-\sin \left(2 \pi \frac{t}{T_{s}}\right)\right] ; 0 \leq t \leq T_{s} \\
& z_{s}(t)=\left\{\begin{array}{l}
\frac{\text { Height }}{2 \pi}\left[2 \pi \frac{t}{\rho T_{s}}-\sin \left(2 \pi \frac{t}{\rho T}\right)\right] \\
\text { Height }-\frac{\text { Height }}{2 \pi}\left[2 \pi \frac{t-\rho T_{s}}{(1-\rho) T_{s}}-\sin \left(2 \pi \frac{t-\rho T_{s}}{(1-\rho) T_{s}}\right)\right], \rho T_{s} \leq t \leq T_{s}
\end{array}\right. \\
& \text { hip }_{\text {rotation }}=\frac{\mid 1}{T_{s}\left(1-2 T_{\theta C}\right)}
\end{aligned}
$$

\subsection{Fuzzy logic controller (FLC)}

Originally advocated by Zadeh [25] and Mamdani and Assilian [26], fuzzy has become a mean of collecting human knowledge and experience and dealing with uncertainties in the control system process as shown in Figure 9(a). The design of fuzzy logic controller generally has the following steps:

a. Design the membership function for fuzzification input and output variables.

b. Implement the fuzzy inference by a series of IF- THEN rules.

c. Inference engine derives a conclusion from the facts and rules contained in the knowledge base using various human expert techniques.

d. Design of defuzification for converting fuzzy data into numerical data that can be transmitted to the control equipment.

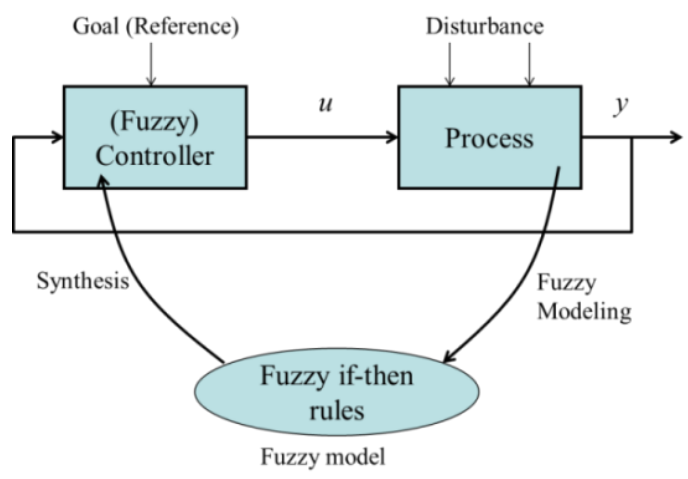

(a)

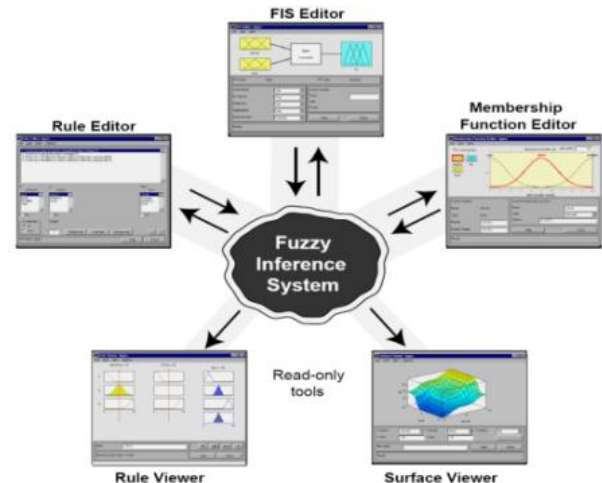

(b)

Figure 9. (a) Fuzzy architectures and (b) Fuzzy inference system (FIS) from MATLAB

MATLAB® Fuzzy Logic Toolbox is used to aid in FLC design as shown in Figure 9(b). The toolbox contains functions, graphical user interfaces and data structures that allow the user to quickly design, test, simulate and modify a fuzzy inference system. In this paper using Mamdani fuzzy rules as inference rules. This method is often also known as Max-Min method. This method was introduced by Ebrahim Mamdani in 1975. 
To obtain the output fuzzy, it takes four stages:

1. Fuzzification is the process of transforming crisp values into degree of membership for linguistic terms of fuzzy sets. In this paper using three types of analysis of fuzzy set membership in fuzzification process, there are listed as follows.

a. The upgraded fuzzy membership function is described in Figure 10(a) and Equation (14).

$$
\mu=\left\{\begin{array}{cc}
0 & x \leq a \\
\frac{(x-a)}{(b-a)} & a<x \leq b
\end{array}\right.
$$

b. The downward fuzzy membership function is described in Figure 10(b) and Equation (15).

$$
\mu=\left\{\begin{array}{cc}
0 & x \leq a \\
\frac{(x-a)}{(b-a)} & a<x \leq b
\end{array}\right.
$$

c. The membership function of the triangular fuzzy is described in Figure 10(c) and equation (16).

$$
\mu= \begin{cases}\frac{(b-x)}{(b-a)} & a \leq x<b \\ \frac{(x-a)}{(b-a)} & b<x \leq c\end{cases}
$$

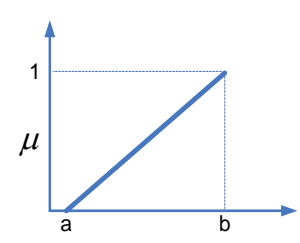

(a)

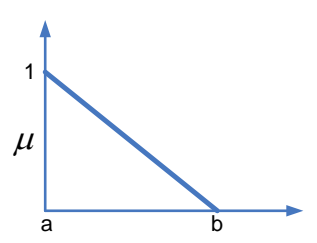

(b)

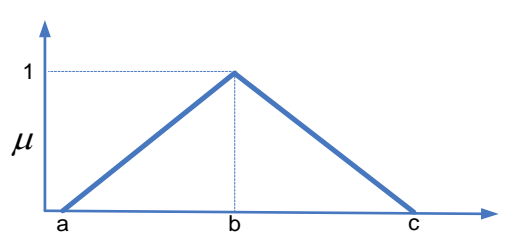

(c)

Figure 10. Type of membership function in Fuzzy; (a) upgraded fuzzy, (b) downward fuzzy,

(c) triangular fuzzy

2. The fuzzy implication is to evaluate the consequent part of each rule. Among various implication methods available in the literature, Mamdani implication method is selected. After the inputs have been fuzzified, and fuzzy logic control knows the degree to which part of the antecedent rule is satisfied. The equation of Mamdani method to verify the fuzzy implication is in (17).

$$
\mu_{y}(k)=\max \left[\min \left\{\mu_{u}(k), \mu_{r}(\operatorname{error}(i), \operatorname{derror}(j))\right\}\right]
$$

3. Generating the rules for a fuzzy control system is often the most difficult step in the design process. It usually requires some expert knowledge of the plant dynamics. There are three methods used in fuzzy system inference, namely: max, additive and probabilistic OR. In the max method, the fuzzy set solution is obtained by retrieving the rule maximum value, then using it to modify the fuzzy region, and applying it to the output using the OR (union) operator.

4. We proposed weight average (WA) for defuzzification stage [27]. The WA calculation is described in (18) using three singletons membership function

$$
W A=\frac{\mu(k 1) \times k 1+\mu(k 2) \times k 2+\mu(k 3) \times k 3}{\mu(k 1)+\mu(k 2)+\mu(k 3)}
$$




\section{FUZZY SYSTEM ARCHITECTURES}

\subsection{Fuzzy logic controller on CoP region stability}

The FLC is one of the effective methods to control a system which is hard to model clearly, like a bipedal robot system. The control algorithm can be interpreted and formulated by expert knowledge. Before designing the FLC, the desired control goal should be defined first. In this section, we described the FLC on CoP region's stability. The basic idea is to keep balance the CoP position of a bipedal robot when walks. In SSP, the CoP position should be located inside the sole of the foot. On the other hand, it should be located between the two feet in the DSP as illustrated in Figure 11.

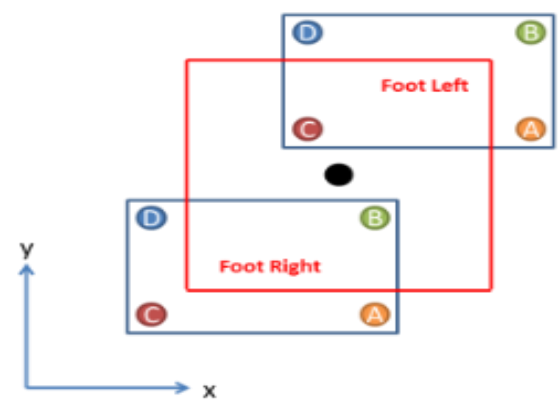

(a)

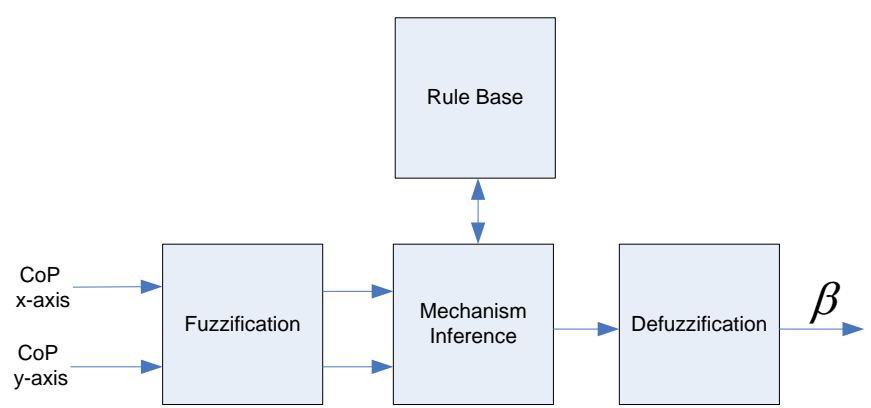

(b)

Figure 11. (a) CoP position of bipedal robot when walks at DSP phase and (b) the FLC design in stability region
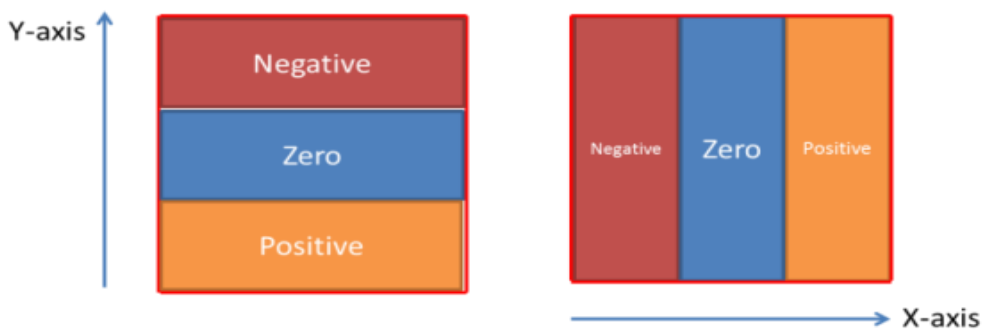

Figure 12. The $\mathrm{x}$-axis and $\mathrm{y}$-axis of margin stability region

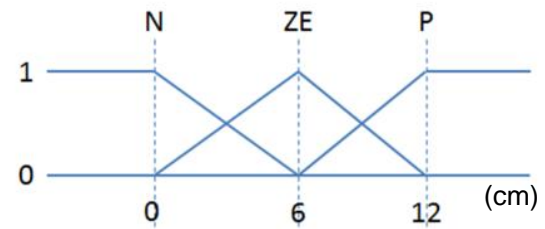

Fuzzification membership function $\mathrm{x}$-axis

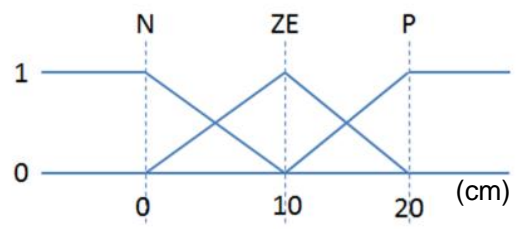

Fuzzification membership function $y$-axis

(b)

(a)

Figure 13. Fuzzification (a) x-axis, (b) y-axis membership function of CoP region's stability

From the result of determining CoP position, we are able to define the area of CoP position as the input of our FLC system. In x-axis and y-axis of margin stability region as shown in Figure 12, we can define three memberships of fuzzy sets, $\mathrm{N}$ (Negative), Z (Zero) and P (Positive). After a fuzzification process of a fuzzy set $\mathrm{x}$-axis and $\mathrm{y}$-axis, we constructed rule based FLC in order to keep the CoP position still inside of stability regions. The relationship between $\mathrm{CoP}$ position on the $\mathrm{x}$-axis and $\mathrm{y}$-axis will be implicated by using 
Table 2. The fuzzification $\mathrm{x}$-axis and $\mathrm{y}$-axis are using triangle membership function with 3 fuzzy sets as shown in Figure 13. The length value of membership function for $x$-axis and y-axis are $12 \mathrm{~cm}$ and $20 \mathrm{~cm}$ as indicated the total foot length of the robot.

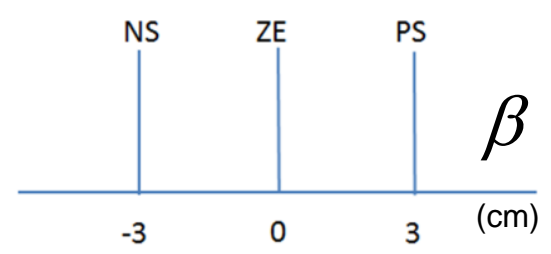

Defuzzification with 3 set singleton

Figure 14. defuzzification membership function of CoP region's stability

Table 2. Rule base for CoP region's Stability

\begin{tabular}{|c|c|c|c|}
\hline & Negative (N) & Zero (Z) & Positive (P) \\
\hline Negative (N) & 0 & Z & 0 \\
\hline Zero (Z) & $\mathrm{N}$ & Z & $P$ \\
\hline Positive (P) & 0 & Z & 0 \\
\hline
\end{tabular}

The next stage is defuzzification. The membership function of this stage is described in Figure 14. The result of defuzzification on this case is the length of hip_x_offset. This length will use for adjusting the robot body posture tends to lean backward or forwards. When the robot walking on uneven terrain as shown in Figure 15, the feedback of CoP position will be evaluated by FLC, and then output this controller will adjust the hip_x_offset

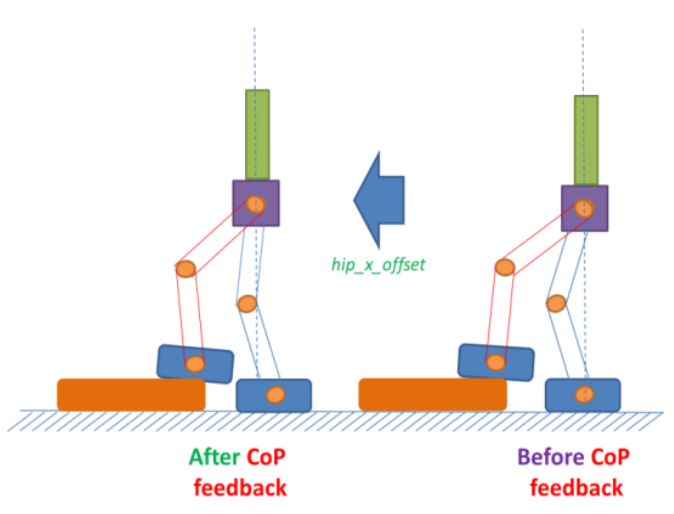

Figure 15. Body posture changes after CoP feedback

\subsection{Fuzzy logic on stable compliance control}

In this section, we explained the compliance control with implementing using FLC. The basic idea is to keep balance the bipedal robot when any force applied on the feet. For an example, when we pushed the robot from the back side. The measurement of force sensor on front side feet more than back as illustrated in Figure 16. 


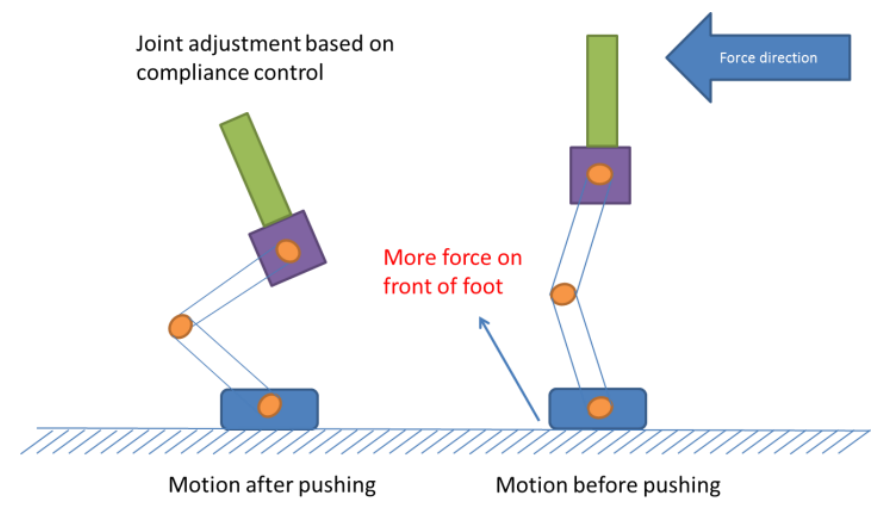

Figure 16. Motion after and before pushing from back direction

In compliance control, we also measure and consider the CoP position of bipedal robot. In the ideal condition, when the bipedal robot stand-up on DSP, the position of CoP will in the center (black circle) as shown in Figure 17(a). The stability margin, red line rectangle is used to avoid and boundaries the CoP position which still inside of stability margin. By knowing the real position of CoP, we will know the real condition of bipedal robot. For example, when the CoP position at condition 1 (see Figure 17(b), we can measure the average force on points B and D at foot left. If the force point B and D at foot left more than our force limitation which is mean more force on left side foot. Thus, we can define the error as in (19).

$$
\text { |error } \mid=\text { positive pitchbodylimitation-pitchbodyrobotmeasurement }
$$

Furthermore, if we know the error, we could calculate the delta error as indicated in (20).

$$
\mid \text { deltaerror } \mid=\text { error-lasterror }
$$

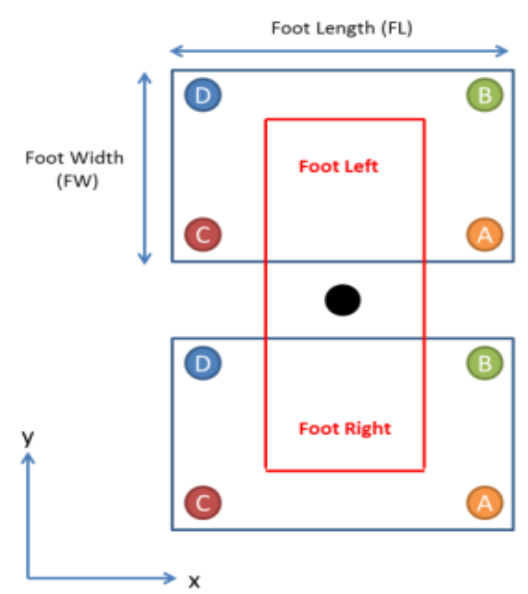

(a)

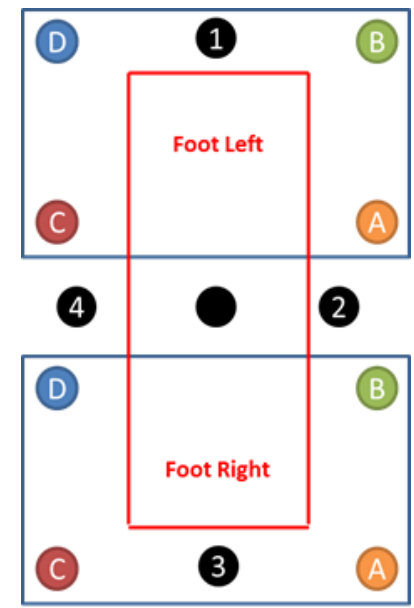

(b)

Figure 17. (a) CoP position of bipedal robot when stand up at DSP phase (b) four categories of CoP position and its condition

After computing the absolute error and the absolute delta error as indicated in Equations (19) and (20), these data are taken as input variables of the designed FLC for condition 1 case as shown in Figure 18. The ouput process of defuzzifiction is offset joint $(\varnothing)$. 


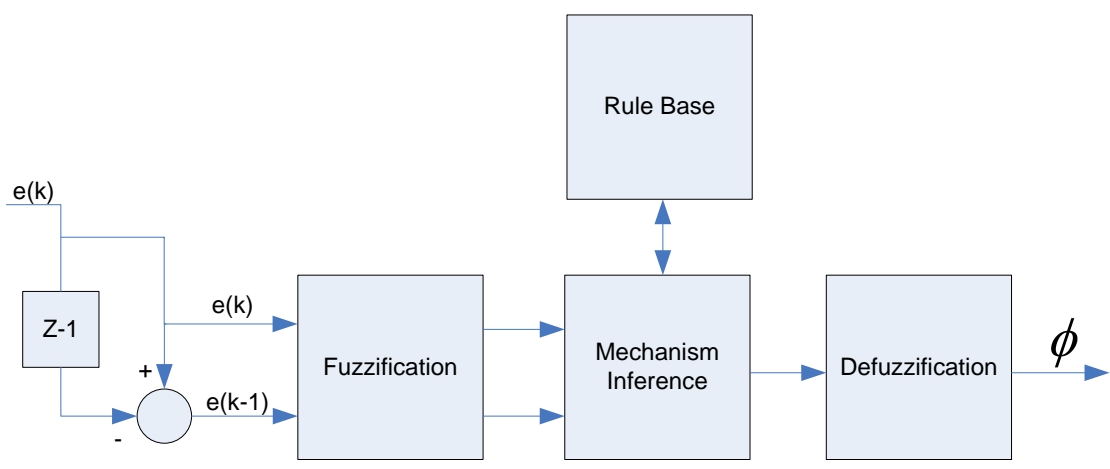

Figure 18. The FLC design in stable compliance control

The specification of fuzzy design are explained as follows: 1) fuzzification error and delta error using triangle membership function with 5 fuzzy sets as shown in Figure 19,2) rule base evaluation using MacVicar Whelan style inference as shown in Table 3, and 3) defuzzification using 5 set singletons as shown in Figure 20 .

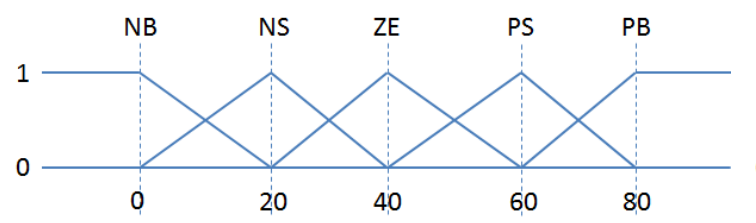

Fuzzification membership function error

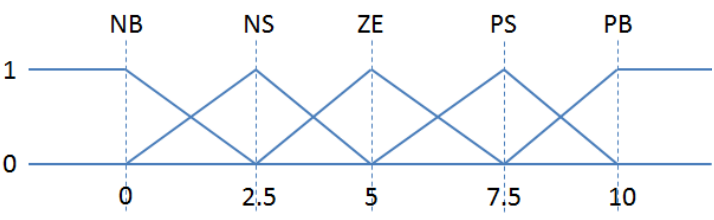

Fuzzification membership function derror

Figure 19. Fuzzification membership function on compliance control

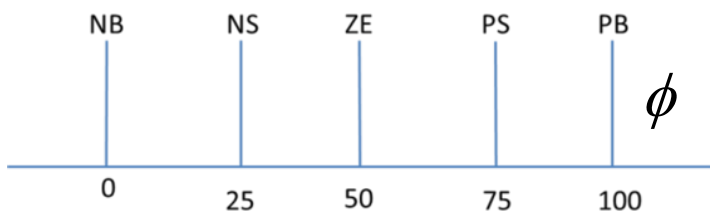

Defuzzification with 5 set singleton

Figure 20. Defuzzification membership function on compliance control

Table 3. Rule base for Compliance Control

\begin{tabular}{|c|c|c|c|c|c|c|}
\hline & \multicolumn{6}{|c|}{ error } \\
\hline & & $\begin{array}{l}\text { Very Small } \\
\text { (NB) }\end{array}$ & $\begin{array}{l}\text { Small } \\
\text { (NS) }\end{array}$ & $\begin{array}{l}\text { Medium } \\
\text { (Z) }\end{array}$ & $\begin{array}{l}\text { Large } \\
\text { (PS) }\end{array}$ & $\begin{array}{l}\text { Very Large } \\
\text { (PB) }\end{array}$ \\
\hline \multirow{5}{*}{ derror } & $\begin{array}{l}\text { Very Small } \\
\text { (NB) }\end{array}$ & NB & NB & NS & NS & z \\
\hline & $\begin{array}{l}\text { Small } \\
\text { (NS) }\end{array}$ & NB & NS & NS & z & PS \\
\hline & $\begin{array}{l}\text { Medium } \\
\text { (z) }\end{array}$ & NS & NS & z & PS & PS \\
\hline & $\begin{array}{l}\text { Large } \\
\text { (PS) }\end{array}$ & NS & $z$ & PS & PS & PB \\
\hline & $\begin{array}{l}\text { Very Large } \\
\text { (PB) }\end{array}$ & z & PS & PS & PB & PB \\
\hline
\end{tabular}

After the defuzzification process, we get one output $(\varnothing)$ that will be used as value offset joint on ankle, knee, and hip as explained in Figure 21(a) and Figure 21(b). 


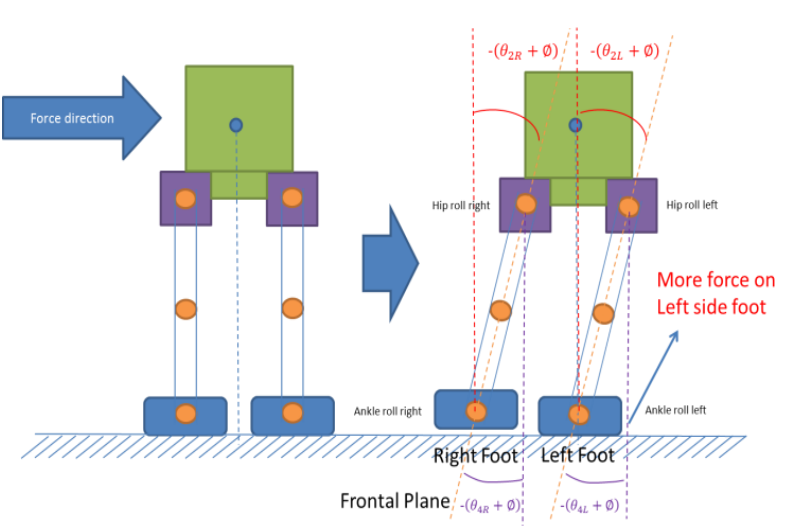

(a)

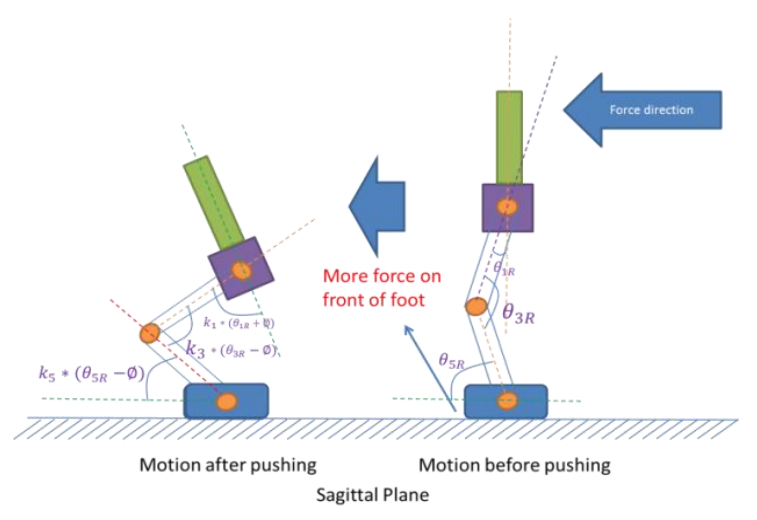

(b)

Figure 21. (a) Motion before and after at compliance control for condition and (b) Motion before and after at compliance control for condition 2

Figure 21(a) is described when the bipedal robot in condition 1. In this situation, the value output from defuzzification is theta offset $\phi$ that will be used to adjust the joint offset of roll for hip-left, ankle-left and also right. The formulation of this case is indicated in (21).

$$
\begin{aligned}
& \text { hip_roll_left }=-\left(\theta_{2 L}+\phi\right) \\
& \text { ankle_roll_left }=-\left(\theta_{4 L}+\phi\right) \\
& \text { hip_roll_right }=-\left(\theta_{2 R}+\phi\right) \\
& \text { ankle_roll_right }=-\left(\theta_{4 R}+\phi\right)
\end{aligned}
$$

For condition 3, the formula is indicated in (22).

$$
\begin{aligned}
& \text { hip_roll_left }=\left(\theta_{2 L}+\phi\right) \\
& \text { ankle_roll_left }=\left(\theta_{4 L}+\phi\right) \\
& \text { hip_roll_right }=\left(\theta_{2 R}+\phi\right) \\
& \text { ankle_roll_right }=\left(\theta_{4 R}+\phi\right)
\end{aligned}
$$

Figure 21(b) is described the bipedal robot in condition 2. In this situation, the value output from defuzzification is theta offset $\phi$ that will be used to adjust the joint offset of pitch for the hip-left, knee-left, ankle-left and also right. The formulation of this case is indicated in (23).

$$
\begin{aligned}
& \text { hip_pitch_left }=k_{1} *\left(\theta_{1 L}+\phi\right) \\
& \text { hip_pitch_right }=k_{1} *\left(\theta_{1 R}+\phi\right) \\
& \text { knee_pitch_left }=k_{3} *\left(\theta_{3 L}-\phi\right) \\
& \text { knee_pitch_right }=k_{3} *\left(\theta_{3 R}-\phi\right) \\
& \text { ankle_pitch_left }=k_{5} *\left(\theta_{5 L}-\phi\right) \\
& \text { ankle_pitch_right }=k_{5} *\left(\theta_{5 R}-\phi\right)
\end{aligned}
$$

For condition 4, the formula is indicated in (24). 


$$
\begin{aligned}
& \text { hip_pitch_left }=-\left(k_{1} *\left(\theta_{1 L}+\phi\right)\right) \\
& \text { hip_pitch_right }=-\left(k_{1} *\left(\theta_{1 R}+\phi\right)\right) \\
& \text { knee_pitch_left }=-\left(k_{3} *\left(\theta_{3 L}-\phi\right)\right) \\
& \text { knee_pitch_right }=-\left(k_{3} *\left(\theta_{3 R}-\phi\right)\right) \\
& \text { ankle_pitch_left }=-\left(k_{5} *\left(\theta_{5 L}-\phi\right)\right) \\
& \text { ankle_pitch_right }=-\left(k_{5} *\left(\theta_{5 R}-\phi\right)\right)
\end{aligned}
$$

\section{RESULTS AND ANALYSIS}

\subsection{Bipedal platform}

In this paper, we used HuroEvolutionJR kid-size bipedal robot from Medical Robot Laboratory (MRL) National Taiwan University of Science and Technology. The HuroEvolutionJR is designed as an eighteen degree-of-freedom (DOF); where 12 DOF joints are desired for two legs, 4 DOF joints are desired for two arms, and 2 DOF joints are desired for the head. The height and the total weight including the batteries are $380 \mathrm{~mm}$ and 2900 gram, respectively. The mechanical structure of is shown in Figure 22(a).

The electronic design of HuroEvolutionJR is shown in Figure 22(b), we used Arduino DUE ARM (Advanced RISC Machine) 32-bit microcontroller, namely Atmel SAM3X8E ARM Cortex-M3 CPU with 84 $\mathrm{MHz}$ speed of frequency clocks. The Arduino DUE is used for motion controller with deals for trajectory patterns such as Linear Inverted Pendulum Model (LIPM), Inertial Measurement Unit (IMU) sensor processing, and FSR sensor processing. This motion controller will have communication data with personal computers (PC) and remote control device using serial data communication.

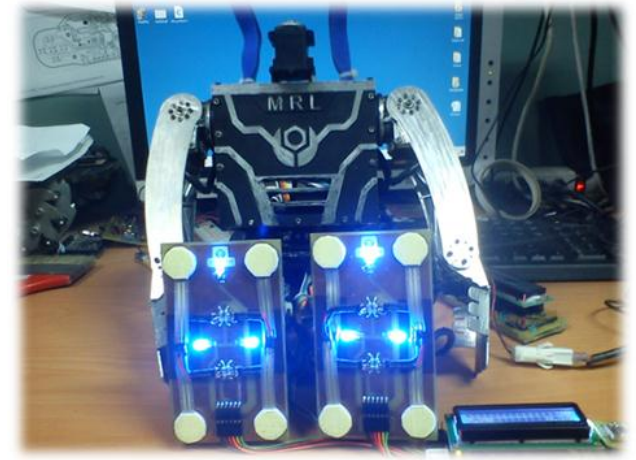

(a)

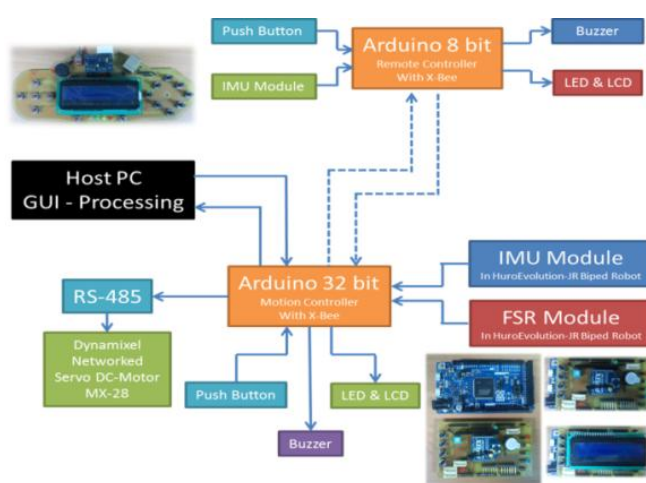

(b)

Figure 22. (a) Physical of the HuroEvolution ${ }^{\mathrm{JR}}$ (b) Electronic architectures

\subsection{Simulation result}

In order to verify the CoP equations on SSP and DSP, simulation by using MATLAB was applied before implement it on the bipedal robot. Two condition simulations (SSP or DSP) is shown in Figure 23. In this simulation, the force value is begins from 0 (indicated that no pressure) until 255 (indicated that high pressure). Futhermore, we also developed graphical user interface (GUI) to diplay foot pad sensor condition in realtime to evaluate the $\mathrm{CoP}$ conditions during static and dynamic walking as shown in Figure 24. This GUI is developed by Processing IDE. 

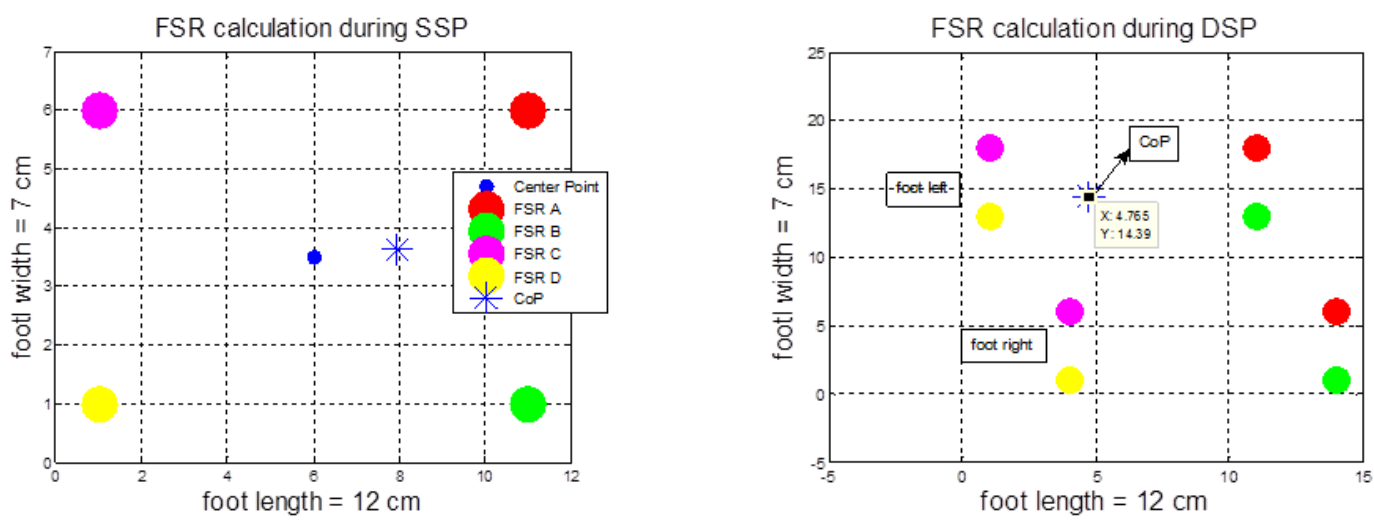

Figure 23. CoP position during SSP with $\mathrm{fA}=192, \mathrm{fB}=128, \mathrm{fC}=50, \mathrm{fD}=90$ [left] and CoP position during DSP with displacement $=3 \mathrm{~cm}, \mathrm{fA} 1=125, \mathrm{fB} 1=56, \mathrm{fC} 1=238, \mathrm{fD} 1=43, \mathrm{fA} 2=0, \mathrm{fB} 2=0, \mathrm{fC} 2=12, \mathrm{fD} 2=80$ [right]

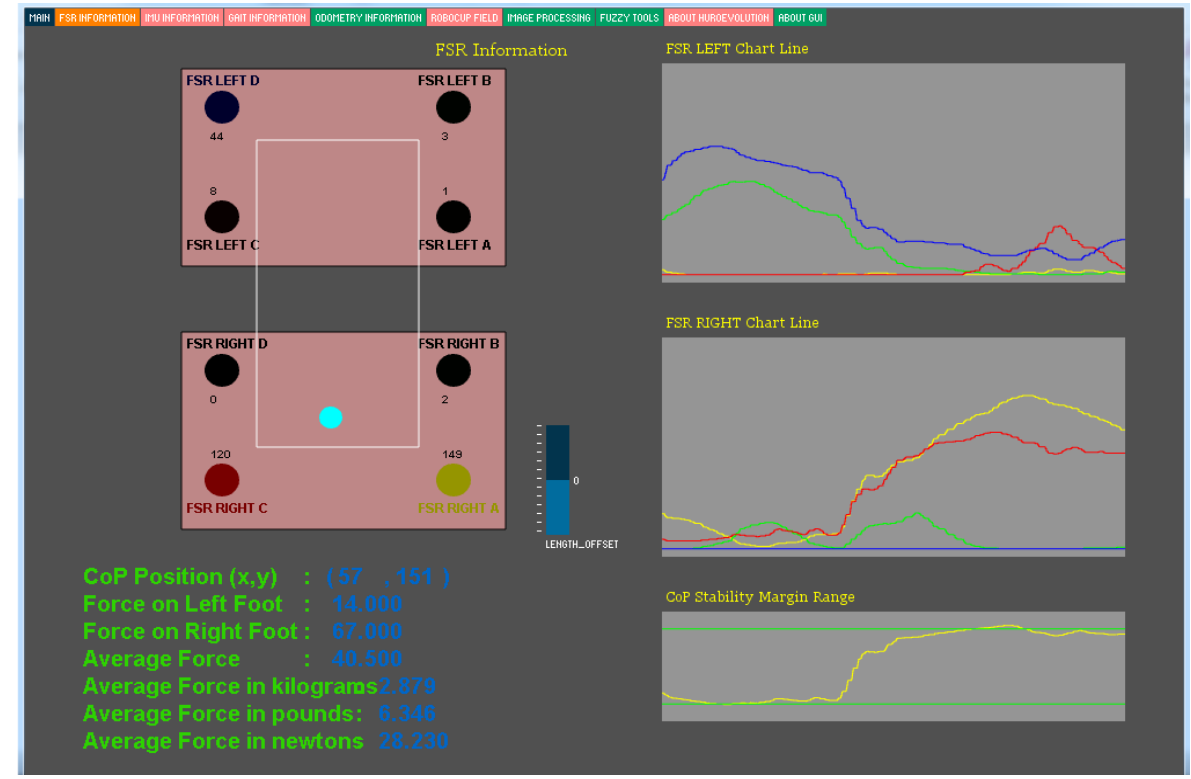

Figure 24. CoP position when simulate in GUI, CoP position changes to right

\subsection{Experimental result}

When the bipedal robot moves, the $\mathrm{CoP}$ trajectory was used to evaluate the CoP position which still inside of the CoP margin stability range or inside of support polygon as shown in Figure 26(a). For analyzing the result, a single walking cycle was divided into four parts: In Figure 25 shown that phase A-B is the first lifting of the right leg. Phase B-C is SSP on the right foot. Phase C-D is SSP on the left foot. And D-E phase is SSP on the right foot, this process will be repeated.

There are three cases in order to verify the compliance control based on CoP condition and the force when applied in feet of the robot. Case one, when the CoP position changing to the left side of the robot as shown in Figure 28. Case two, when the CoP position changing to the front side of the robot as depicted in Figure 29(a) to Figure 29(b). Case three, when the CoP position changing to the back side of the robot as shown in Figure 29(c) to Figure 29(d). The fuzzy logic that applied in these cases is able to achieve for keeping balance the body posture of the robot. The response of error, delta error and the output of defuzzification will be shown in Figure 26(b). The parameter of membership function fuzzification error and delta error are tuned by experiment with GUI shown in Figure 27. Finally, Figure 30 is shown the conditions of a bipedal robot when walks in uneven terrain. All video experiments were upload at YouTube channel in [28]. 
Leg right Leg left

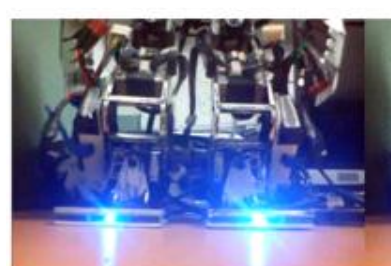

DSP
Leg right

Leg left

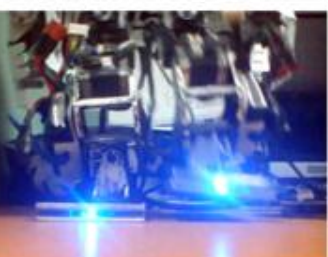

SSP right foot

BC-Phase
Leg right Leg left

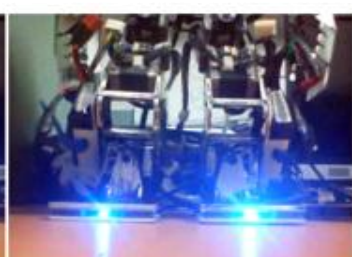

DSP
Leg right Leg left

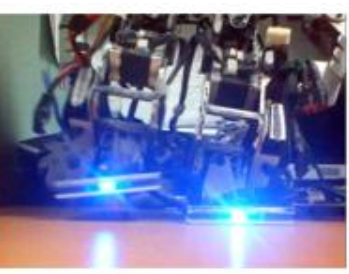

SSP left foot

CD-Phase

Figure 25. The video capture during the robot's walking

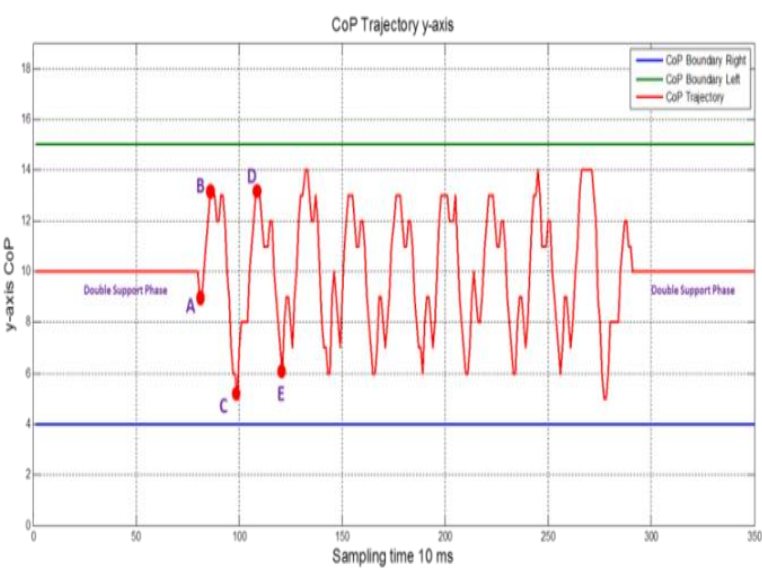

(a)

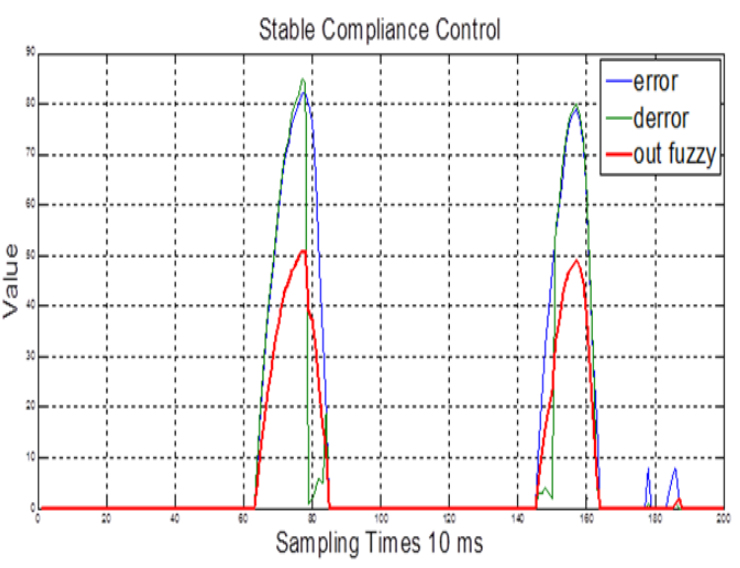

(b)

Figure 26. (a) The signals response error, derror and (b) Ouput fuzzy when CoP position changing to left side

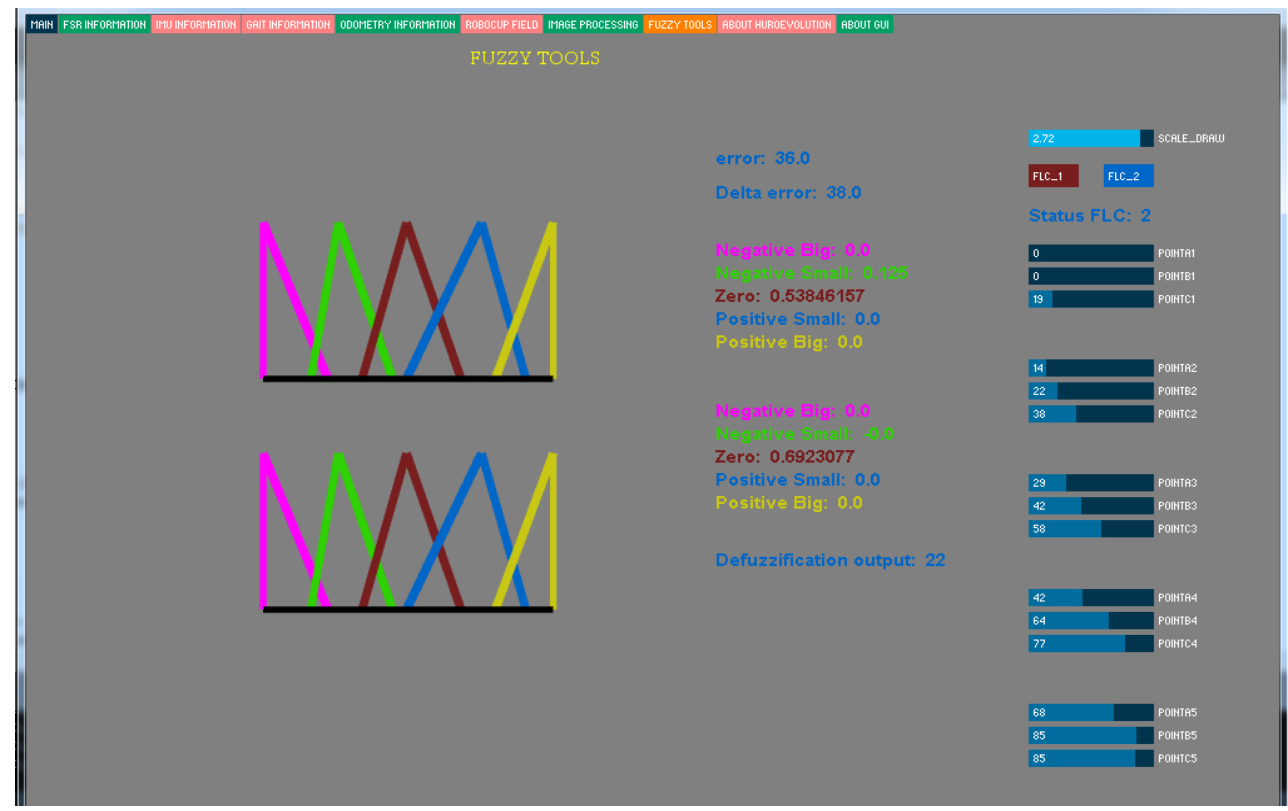

Figure 27. Fuzzy logic tools GUI to evaluate the output of fuzzy 


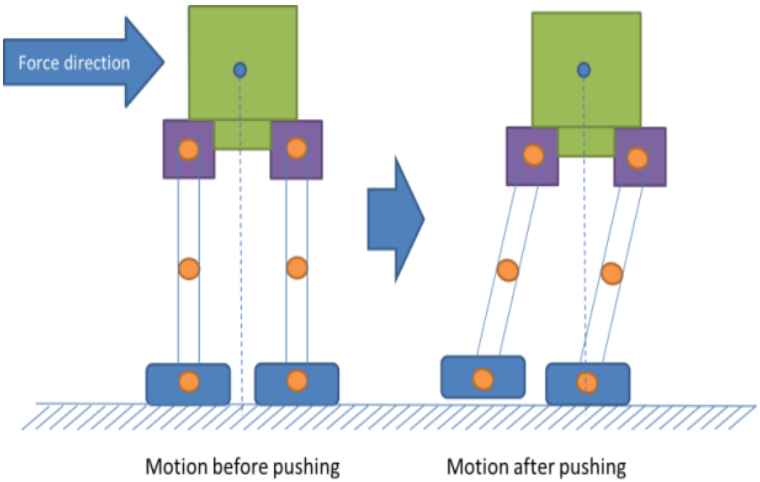

(a)
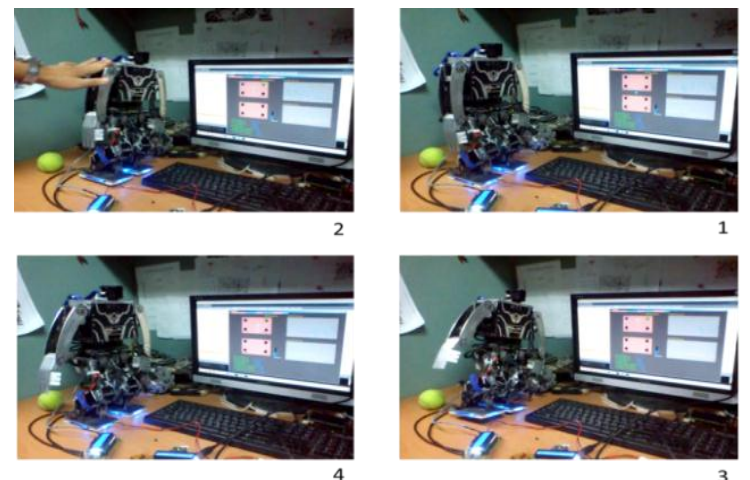

(b)

Figure 28. Stable compliance control when CoP position changing to left side; (a) ilustration (b) real condition record
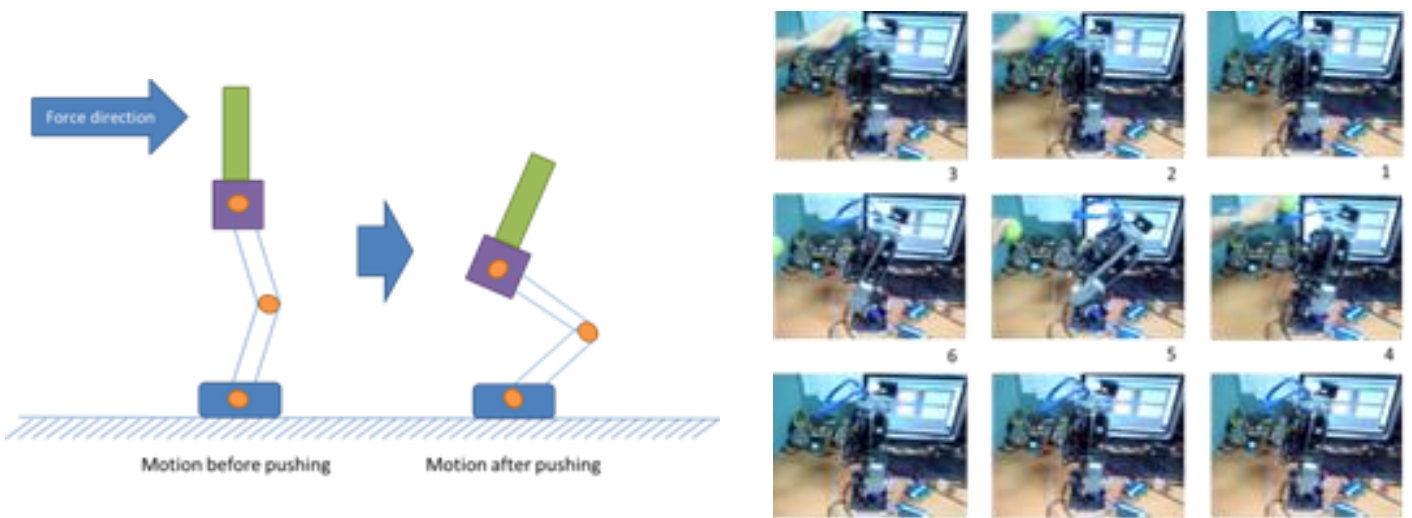

Motion before pushing
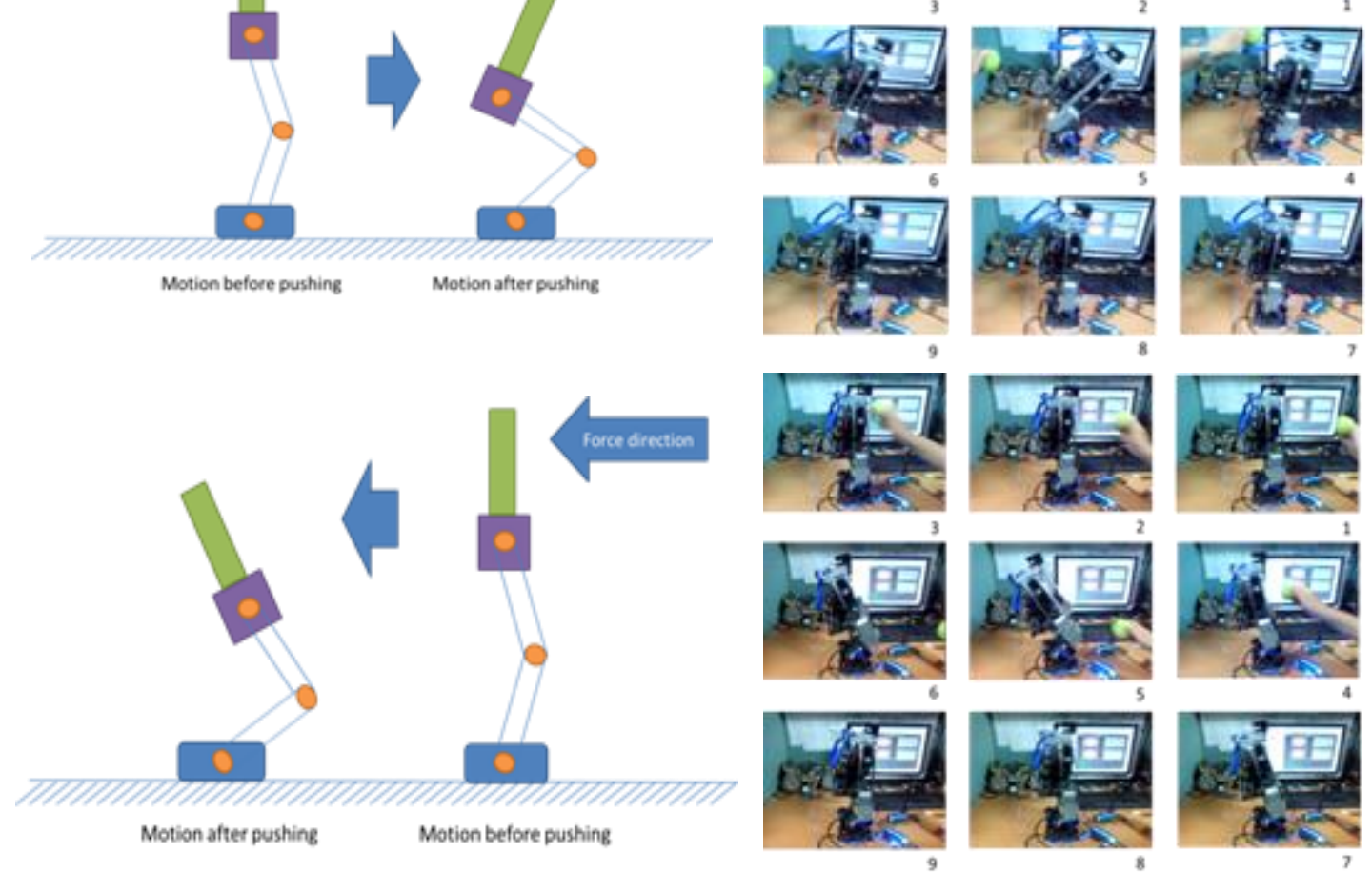

Figure 29. Stable compliance control when CoP position changing to front side; (a) ilustration (b) real condition record and Stable compliance control when CoP position changing to back side; (c) ilustration $(\mathrm{d})$ real condition record 


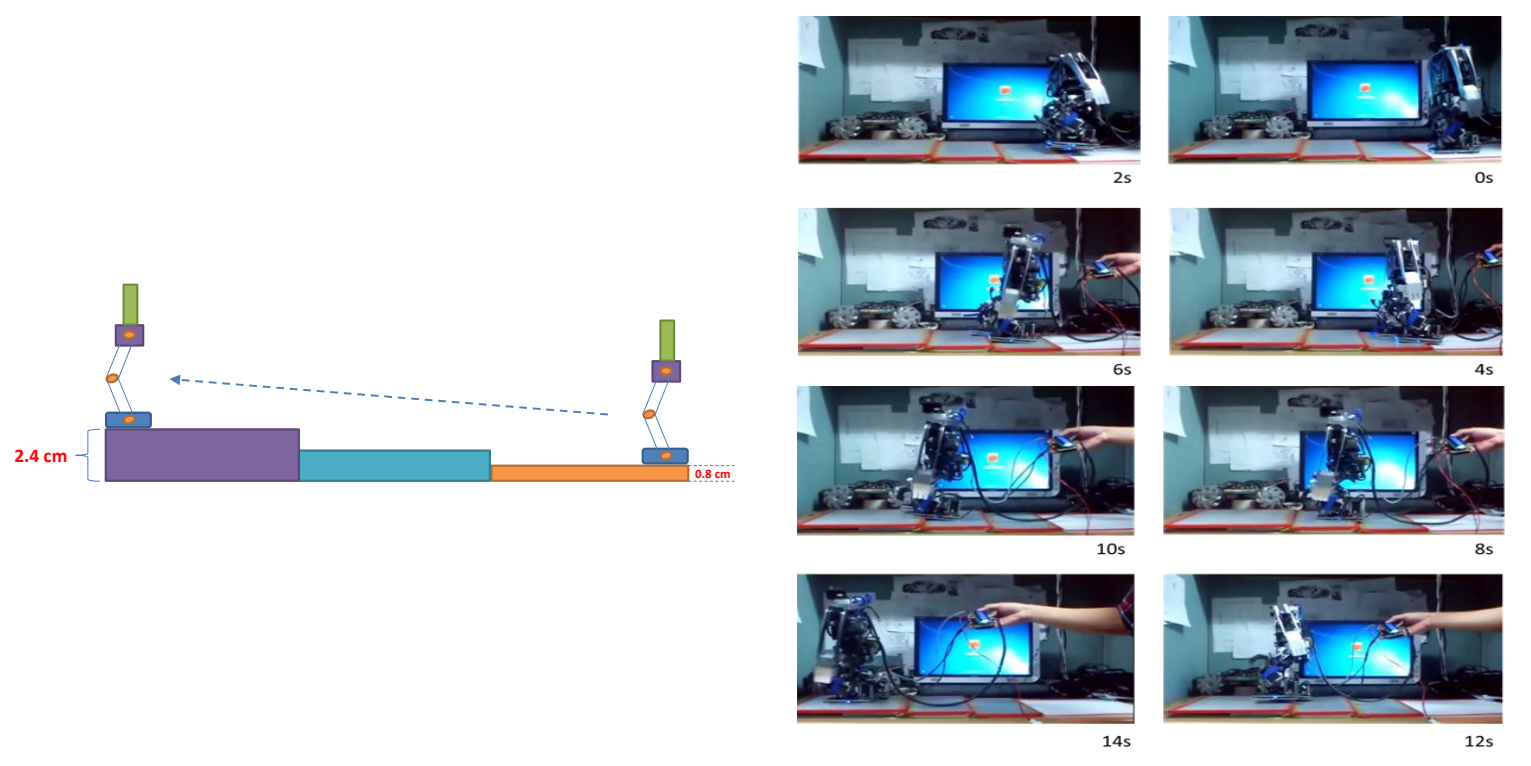

Figure 30. Stable compliance control when CoP position changing to front side

\section{CONCLUSION}

In this paper, a method of controlling bipedal robots to walk stably is proposed based on FSR sensor. Fuzzy logic control (FLC) was used for two cases. The first was for stable compliance control and the second was CoP region's stability. In compliance control mode, the designed FLC accepts inputs from error and delta error of force limitation and generate theta offset that used as feedback to adjust the body posture of a bipedal robot. In CoP region's stability mode, the designed fuzzy controller accepts inputs from x-axis and $\mathrm{y}$-axis of CoP position and changes the robot body posture tends to lean backwards or forwards.

Eventually, several experiments showed that the designed of FLC able to make the robot walks stable on uneven terrain. For future works, this system can be added with another sensor like vision. With vision perception, the robot can recognize the terrain condition in environments so when the robot walks in an uneven terrain, the recognized terrain condition would provide useful information.

\section{ACKNOWLEDGEMENTS}

The authors wish to thank Medical Robot Laboratory National Taiwan University of Science and Technology for facilities to use HuroEvolutionJR during his study and to Graduate School of Science Education, University of Bengkulu, for supporting this work.

\section{REFERENCES}

[1] Monteiro, et al., "Humanoid Dynamic Controller", TELKOMNIKA (Telecommunication, Computing, Electronics and Control), vol. 10, no. 8, pp. 1936-1947, 2012.

[2] Lipeng, Y. U. A. N., Amur Al Yahmedi, and Liming Yuan, "Optimized Passive Coupling Control for Biped Robot", Indonesian Journal of Electrical Engineering and Computer Science, vol. 11, no. 6, pp. 3044-3052, 2013.

[3] C.L. Shih, "Ascending and Descending stairs for a Biped Robot", Systems, Man and Cybernetics, Part A: Systems and Humans, IEEE Transactions, vol. 29, pp. 255-268, 1999.

[4] Y.F. Zheng and J. Shen, "Gait Synthesis for the SD-2 Biped Robot to climb sloping surface", Robotics and Automation, IEEE Transactions, vol. 6, pp. 86-96, 1990.

[5] C. Fu and K. Chen, "Gait Synthesis and Sensory Control of stair climbing for a Humanoid Robot", Industrial Electronics, IEEE Transactions, vol. 55, pp. 2111-2120, 2008.

[6] E. Ohashi, T. Aiko, T. Tsuji, H. Nishi, and K. Ohnishi, "Collision Avoidance Method of Humanoid Robot with arm force", Industrial Electronics, IEEE Transactions, vol. 54, pp. 1632-1641, 2007.

[7] Cui, Yifeng, et al. "Control Structure Design for Man-Function Humanoid Robot." Indonesian Journal of Electrical Engineering and Computer Science, vol. 11 no. 12, 3222222.L36L, pp. 7745-7753, 2013.

[8] Kajita, et al., "Biped walking Pattern Generation by using preview Control of zero-moment Point", In Robotics and Automation, 2003. Proceedings. ICRA'03. IEEE International Conference on, vol. 2, pp. 1620-1626, IEEE, 2003.

[9] Sardain, Philippe, and Guy Bessonnet, "Forces Acting on a Biped Robot Center of Pressure-zero Moment Point", IEEE Transactions on Systems, Man, and Cybernetics-Part A: Systems and Humans, vol. 34, no. 5, pp. 630-637, 2004.

Center of Pressure Feedback for Controlling the Walking Stability Bipedal Robots using ... (Afrizal Mayub) 
[10] Mitobe, Kazuhisa, Genci Capi, and Yasuo Nasu, "Control of walking Robots based on Manipulation of the zero Moment Point", Robotica, vol. 18, no. 6, pp. 651-657, 2000.

[11] Kim, Jung-Yup, Ill-Woo Park, and Jun-Ho Oh, "Experimental Realization of Dynamic walking of the Biped Humanoid Robot KHR-2 using zero Moment Point Feedback and Inertial Measurement", Advanced Robotics, vol. 20 , no. 6, pp. 707-736, 2006.

[12] Sugihara, Tomomichi, Yoshihiko Nakamura, and Hirochika Inoue, "Real-time Humanoid Motion Generation through ZMP Manipulation based on Inverted Pendulum Control”, In Robotics and Automation, 2002. Proceedings. ICRA'02. IEEE International Conference on, vol. 2, pp. 1404-1409, IEEE, 2002.

[13] Erbatur, Kemalettin, and Okan Kurt, "Natural ZMP Trajectories for Biped Robot Reference Generation”, IEEE Transactions on Industrial Electronics, vol. 56, no. 3, pp. 835-845, 2009.

[14] Al-Shuka, Hayder FN, Burkhard J. Corves, Bram Vanderborght, and Zhu Wen-Hong., "Zero-Moment Point-Based Biped Robot with Different Walking Patterns", International Journal of Intelligent Systems and Applications, vol. 7, no. 1, p. 31, 2014.

[15] Choi, Kyu-Cheon, Hyun-Jeong Lee, and Min Cheol Lee, "Fuzzy Posture Control for Biped walking Robot based on force Sensor for ZMP”, In SICE-ICASE, 2006. International Joint Conference, pp. 1185-1189, IEEE, 2006.

[16] Claros, M., J. J. Rodriguez, and Rogelio Soto, "Balance Control of a Biped Robot in the Coronal plane using foot sole CoP Trajectories", In Control \& Automation (ICCA), 11th IEEE International Conference on, pp. 661-666, IEEE, 2014.

[17] Sardain, Philippe, and Guy Bessonnet, "Zero Moment Point-measurements from a Human walker wearing Robot feet as shoes", IEEE Transactions on Systems, Man, and Cybernetics-Part A: Systems and Humans, vol. 34, no. 5, pp. 638-648, 2004.

[18] Minakata, Hideaki, Hirokazu Seki, and Susumu Tadakuma, "A Study of Energy-saving shoes for Robot Considering Lateral plane Motion", IEEE Transactions on Industrial Electronics, vol. 55, no. 3, pp. 1271-1276, 2008.

[19] Suwanratchatamanee, Kitti, Mitsuharu Matsumoto, and Shuji Hashimoto, "Haptic Sensing foot System for Humanoid Robot and ground recognition with one-leg balance", IEEE Transactions on Industrial Electronics, vol. 58, no. 8, pp. 3174-3186, 2011.

[20] Choi, Kyu-Cheon, Hyun-Jeong Lee, and Min Cheol Lee, "Fuzzy Posture Control for Biped walking Robot based on force sensor for ZMP", In SICE-ICASE, 2006. International Joint Conference, pp. 1185-1189, IEEE, 2006.

[21] Li, Tzuu-Hseng S., Yu-Te Su, Shao-Hsien Liu, Jhen-Jia Hu, and Ching-Chang Chen, "Dynamic balance Control for Biped Robot walking using Sensor Fusion, Kalman Filter, and Fuzzy Logic", IEEE Transactions on Industrial Electronics, vol. 59, no. 11, pp. 4394-4408, 2012.

[22] M. Vukobratovi 'C and B. Borova'c, "Zero-moment Point - thirty five years of its life", International Journal of Humanoid Robotics, vol. 1, no. 1, pp. 157-173, 2004.

[23] Chevallereau, Christine, et al., "Bipedal Robots: Modeling, Design and walking Synthesis", John Wiley \& Sons, 2013.

[24] Kuo, Chung-Hsien, Fahmizal, and Shih-Lin Wu, "Development of Fuzzy Logic Controllers for Controlling Bipedal Robot Locomotion on Uneven Terrains with IMU Feedbacks", Indian Journal of Science and Technology, vol. 9, no. $28,2016$.

[25] L.A. Zadeh, "Fuzzy Sets", Information and Control, vol. 8 pp. 338-353, 1965.

[26] E.H. Mamdani, S. Assilian, "Application of Fuzzy Algorithms for Control of Simple Dynamic Plant", Proceedings of the Institute of Electrical Engineers, vol. 121, pp. 1585-1588, 1974.

[27] Yoneyama, Jun, Masahiro Nishikawa, Hitoshi Katayama, and Akira Ichikawa, "Output Stabilization of TakagiSugeno Fuzzy Systems”, Fuzzy sets and Systems, vol. 111, no. 2, pp. 253-266, 2000.

[28] Video implementation results of this paper [Online]. Available on: http://youtu.be/RB_gQwXclWk

\section{BIOGRAPHIES OF AUTHORS}

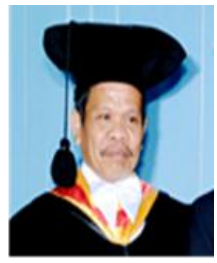

Afrizal Mayub was born on April 18, 1960. He received the Master and Doctor degrees from Universitas Gadjah Mada, Indonesia, in 2003 and 2011. Since 1987, He joined Universitas Bengkulu, Indonesia, as a lecturer. Currently, Dr. Afrizal Mayub is a senior lecturer and researcher in the Graduate School of Science Education, University of Bengkulu. His research interest are robotics, artificial intelligence, physics education and applied science.

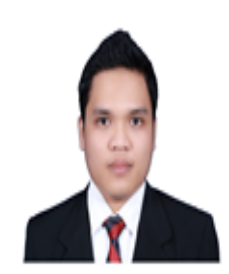

Fahmizal was born on July 23, 1988. He graduated from Master of Science in Taiwan, precisely at National Taiwan University of Science and Technology (Taiwan Tech) in 2014 with cumlaude. Currently, Mr. Fahmizal is a junior lecturer in the Department of Electrical and Informatics Engineering at Vocational College Universitas Gadjah Mada, Indonesia, in the specialist field of the control system and robotics. In addition to actively teaching and researching, Mr. Fahmizal also as adviser and supervisor at Gadjah Mada Robotic Team (GMRT). 